\title{
A third way for health policy?
}

\section{Richard H. Thaler \\ Cass R. Sunstein

\author{
Nudge: Improving Decisions \\ About Health, Wealth, and \\ Happiness
}

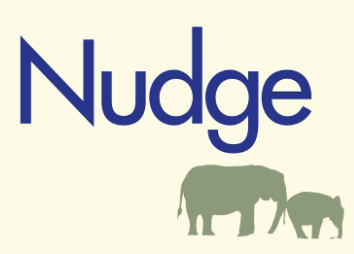

Improving Decisions

About Health, Wealth, and Happiness
Richard H. Thaler, Cass R. Sunstein

Yale University Press, 2012

$320 \mathrm{pp}$, hardcover, $\$ 12.24$

ISBN: 978-0-300-12223-7

Reviewed by Alexander D. Peden

$\mathrm{E}$ conomics has hit the mainstream in the last decade with popular books like Freakonomics and The Undercover Economist reaching the masses. These authors have used their toolkits far beyond the narrow scope of money and finance and answered questions pertaining to anything from social policy to demographics to crime. Their appeal has largely been their ability to explain that small underlying forces can have major impacts, intended or otherwise, on many different areas of society. One recent book following this trend is Nudge, published in 2008 by University of Chicago academics Richard Thaler and Cass Sunstein. The book has attracted acclaim from both journals and the press, with The Financial Times naming it as one of the best business books for 2008 .

Nudge coins the term 'choice architecture', referring to the manner in which a range of alternatives is presented, which the authors contend is commonly overlooked as an integral part of many decisions we all face during the course of our day-today lives (1). When people take the time to judiciously research all alternatives before them, or use their reflective systems in the parlance of the book, they generally make objectively good decisions. Unfortunately, in practice people cannot or do not take the time to do so and instead use their automatic or gut thinking systems, leading to inferior outcomes. The first section of the book then compellingly demonstrates the evidence of its importance in a multitude of situations. There are many lessons to be learned along the way, applicable to both policy-makers and those who wish to critically examine some of their own choices in life. Among these, lessons is the fact that a large

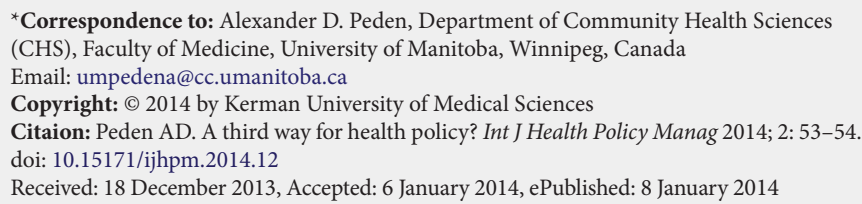

percentage of the population will stick with an easy default option without consideration of better alternatives, even when considering a life-altering decision such as retirement planning. There are even examples of people who fail to take advantage of subsidies to supplement their retirement income by simply not filling out the necessary application form. A further counterintuitive warning for policy-makers is that in some cases, giving people too many choices can lead to worse outcomes as a result of being overwhelmed, or unable to accurately assess them all. Given the evidence, policy-makers should take heed that acknowledging choice architecture can prove as essential to a policy's success as the choices themselves.

Having demonstrated its significance, the authors then present a general philosophy which they term 'paternalistic liberalism' whereby existing policies could be tweaked to subtly encourage or nudge people toward better outcomes. When used properly, this attitude can avoid the problems associated with inflexible mandates without scrapping many of the benefits of regulations. Adopting the authors' philosophy involves using some of the idiosyncrasies of human behavior to their advantage where improved outcomes can be objectively judged. People's gut instincts can often be fooled by the circumstances in which they make their decisions. Almost everyone can think back to poor choices, both large and small, they have made in the past when they rushed an important decision, or followed the herd without considering their unique situation. Instead, nudges could be used to avoid especially difficult choices, such as those that are technical and difficult to comprehend, those that occur rarely and offer little feedback, and those that occur naturally during a moment of temptation. Even strategies that would appear obvious at first glance, such as making the default option ideal for those who do not take the time to choose, are often overlooked in practice. For example, the default option for many programs is non-enrollment for those who fail to apply; instead, automatic enrollment with the option to reject or adjust is often superior, as the policy reaches a larger share of the population, including some of the most vulnerable. The authors present a number of equally intuitive guidelines for designing more user-friendly policies without resorting to heavy-handed regulations and mandates, which often do not account for the diversity of users' needs.

Finally, the book ends with a series of chapters covering a number of specific cases, where adjustments in choice architecture or subtle tweaks in policy could have powerful effects on users' outcomes. Several of these examples have important implications for people's health and well-being. The chapter on financial planning for retirement provides an excellent illustration of the innovative policies the authors provide throughout the book. They state that people regularly report that they should be saving more for retirement, but 
fail to act accordingly when other pressures and temptations come in the way. As a way around this, the authors propose the 'Save More Tomorrow' plan, where users commit in advance to increase their pension contributions when they receive automatic pay raises in the future. Such a system allows people to use their reflective system to make forward-thinking saving plans without having to struggle with painful spending cutbacks. In a pilot study to test this program, participants who initially signed the pledge nearly quadrupled their contribution rates from $3.5 \%$ of income to $13.6 \%$ over the course of three years. Other persuasive suggestions follow for further areas of health policy, such as reforming American Medicare Part D for pharmaceuticals insurance and increasing organ donations in North America.

A thorough, yet entertaining book, this book is a definite must-read for researchers and policy-makers. Its premise is enlightening in demonstrating how only minor adjustments to policies can often be more influential and successful, let alone more feasible, than major overhauls. Moreover, even in the case of those instituting broad changes in policy, many of the book's examples prove how essential it is to concern oneself with many of the intricate details of how the policy will be used by individuals. The example of Sweden privatizing its social security system demonstrates the dangers of ignoring choice architecture; with too many options for personal retirement fund investments, overwhelmed users are unable to properly evaluate all of their options, leading to inferior outcomes. Even the best policies can be brought down if users are not given the best chance to make proper choices.

In a similar manner, researchers could benefit greatly from this book with lessons on where to direct their research. Often, researchers can devote their time solely to estimating the effects of broad policy changes. As stated above, often these are not the only alternatives; many societal benefits could be gained with simple fine-tuning of existing policies, and there is a wealth of research opportunities for those who can identify and study these effects. In addition, one would think that these studies would carry the additional benefit of being more likely to be enacted if research can demonstrate their success, since such adjustments are generally more politically feasible than system overhauls, which often face stiff opposition. Furthermore, even those who are studying broad changes should consider whether minor choice architecture changes could make their results more impressive. In fact, many researchers have begun to follow the authors' advice. Esther Duflo, a standout economist, has done considerable research at the MIT-Poverty Lab concerning policies to alleviate poverty in the developing world. Recently, she published an interesting article measuring whether small nudges building on her previous research in increasing fertilizer use could enhance the success of her programs. By offering time-sensitive discounts in the costs of fertilizer right after the harvest, she found improved results compared to heavy subsidies on their own (2). Researchers across many disciplines could similarly benefit by incorporating elements of this book into their work.

Despite the importance of many of the issues covered by the authors, casual readers should not be put off. The authors use a light-hearted tone throughout the book and the arguments are presented without using economic jargon (though all readers should be careful not to skip the introduction to the book, as it covers several new terms used throughout the book). Furthermore, though many of the policies discussed concern societal policy decisions, others are very applicable to individuals' lives, including chapters on personal finance and health.

With all of the topics the book covers, it seems cruel to take issue with something that is not considered. However, one omission involves the criticism of the use of homo economicus, the theoretical economic man who is capable of instant rational decision-making, throughout economic literature. This is itself one of the main criticisms of the sub-discipline known as behavioral economics, which studies the intricacies of how humans act irrationally in different circumstances. While these criticisms are certainly valid, including those given in this book, it is far more difficult to imagine a better alternative for use in economic research. Even proponents of the use of homo economicus fully understand that it is far from an accurate portrayal of human behavior; however, given its nature, irrationality is very unpredictable, and thus difficult to incorporate into basic models. Although the authors certainly appreciate this, potential readers should understand beforehand that this book does not offer an alternative for its use in fundamental economic models.

Due to its layout, the book covers a number of different unrelated policies in separate chapters. As a result, any readers that are uninterested in a particular topic should not feel obliged to work through them. As long as one reads the first section, all others can be read at one's leisure or in any order without any misunderstandings. In fact, as with any five-year-old book concerning policy, some chapters are slightly out of date. For example, the health section covers Medicare Part D policies and organ donation, and though they are still relevant today, it feels incomplete in today's world without a mention of the Affordable Care Act of 2010. Still, all chapters offer intriguing proposals even to the casual reader.

Overall, by introducing the concept of choice architecture and demonstrating its importance to policy frameworks, Nudge is certainly an important read for anyone involved in the research or formation of public policies. Especially in a world with divisive politics, many of this book's policies represent an interesting example of policies that appear attractive across the political spectrum. Moreover, to the casual reader, it represents a very interesting read that could potentially change the way they see the world.

\section{Ethical issues}

Not applicable.

\section{Competing interests}

The author declares that he has no competing interests.

Author's contribution

ADP is the single author of the manuscript.

\section{References}

1. Thaler R, Sunstein C. Nudge: Improving decisions about health, wealth, and happiness. New Haven: Yale University Press; 2008.

2. Duflo E, Kremer M, Robinson J. Nudging Farmers to Use Fertilizer: Theory and Experimental Evidence from Kenya. Am Econ Rev 2011; 101: 2350-90. 